(c) American Dairy Science Association, 2006.

\title{
Efficacy of Two Hydrogen Peroxide Teat Disinfectants Against Staphylococcus aureus and Streptococcus agalactiae
}

\author{
K. E. Leslie, ${ }^{1}$ E. Vernooy, A. Bashiri, and R. T. Dingwell \\ Department of Population Medicine, Ontario Veterinary College, University of Guelph, Guelph, Ontario N1G 2W1
}

\begin{abstract}
An experimental teat dip containing $0.5 \%$ hydrogen peroxide as the active ingredient was compared with a teat disinfectant also containing $0.5 \%$ hydrogen peroxide that is commercially available throughout North America. The study was conducted under conditions of experimental challenge with a positive control following the guidelines recommended by the National Mastitis Council. The efficacy of the test product and the positive control product were compared in 45 cows, with 89 total teats receiving each product after milking during a 10wk study period. There was no significant difference between the experimental hydrogen peroxide product and the positive control in new intramammary infections caused by Staphylococcus aureus (27.0 and $18.0 \%$ in the treatment groups, respectively). Additionally, there was no significant difference between the experimental product (6.7\%) and the positive control groups $(4.5 \%)$ in new intramammary infections caused by Streptococcus agalactiae. Traditional analysis of teat skin condition changes supported improved teat skin condition with the test disinfectant. After accounting for the correlation of teats within cow, significant differences were also observed between the treatment groups for teat skin condition. The experimental hydrogen peroxide-based teat disinfectant provided efficacy similar to that of the positive control teat disinfectant, with significant improvement in teat skin condition and no adverse effects on teat end condition.
\end{abstract}

Key words: hydrogen peroxide, teat disinfectant, Staphylococcus aureus, positive control challenge

\section{INTRODUCTION}

The processes of premilking udder preparation and postmilking teat disinfection are widely accepted as integral components of a successful mastitis control program (Radostits, 1994). With the large number of teat disinfectants available in the United States and Can-

Received December 12, 2005.

Accepted March 21, 2006.

${ }^{1}$ Corresponding author: keleslie@ovc.uoguelph.ca ada, dairy producers are faced with the decision of selecting a product that has a desirable combination of bactericidal ability and promotion of teat skin health for use in their particular herd situation. Although the efficacy information is oftentimes difficult to obtain and interpret, the National Mastitis Council (NMC) annually publishes a bibliography of peer-reviewed research on the efficacy of commercially available teat disinfectants (National Mastitis Council, 2004). Many of these products are iodophore solutions with excellent efficacy results. The dairy industry has sought efficacious alternatives to iodophore-based postmilking teat disinfectants. It is noteworthy that no publications in the NMC bibliography report the efficacy of a hydrogen peroxidebased teat disinfectant under conditions of challenge exposure. Teat disinfectant manufacturers have made substantial effort to formulate new products that achieve a high efficacy of bactericidal activity while maintaining the integrity of the teat skin condition. Various types and concentrations of emollients are included in these products to ameliorate the impact of the germicide on teat skin. Generally, limited information is available on the effects of these products on teat skin health. Recent teat disinfectant efficacy and safety studies have specifically analyzed teat condition and reported on more intensive evaluations of these products (Boddie et al., 2004; Leslie et al., 2005).

The purpose of the current study was to evaluate the efficacy of a new $0.5 \%$ hydrogen peroxide-based postmilking teat disinfectant in preventing new IMI under conditions of experimental challenge with Staphylococcus aureus and Streptococcus agalactiae in dairy cows in Canada. In addition, teat skin and teat end health were examined. Because it has become a standard recommendation throughout the North American dairy industry to use postmilking teat disinfection, a positive control was used in this study design.

\section{MATERIALS AND METHODS}

\section{Trial Facility and Animals}

A total of 45 Holstein cows located at the Ponsonby Dairy Research Center (PDRC), University of Guelph, were enrolled in the experiment. The PDRC facility is 
a 46-cow tie-stall barn. The lactating cows are housed continuously, with daily exercise from 0800 to $1030 \mathrm{~h}$. The PDRC herd has a monthly herd average SCC linear score of 2.0 to 2.5 and an annual milk production of approximately $10,000 \mathrm{~kg} / \mathrm{cow}$. This experiment was conducted from mid-May through August 2004. All quarters of the trial cows were evaluated throughout the experimental period, except those previously infected with the test organisms and those with severe teat injury.

\section{Udder Preparation and Milking Management}

Trial cows were milked twice daily using a Westfalia Surge automatic take-off milking system (Westfalia Surge Canada Company, Mississauga, Ontario). At every milking, each individual study cow was prepared for milking using the NMC recommended approach for udder preparation as outlined in the laboratory handbook (National Mastitis Council, 1999). During a 3-wk pretrial period, all teats were dipped in an approved, commercially available $0.25 \%$ iodophore premilking teat disinfectant (Della-Pretech, DeLaval Company, Peterborough, Ontario). After milking, all teats were dipped with a commercially available postmilking iodophore teat disinfectant (Teat-Kote, Westfalia-Surge Company). However, during the trial period, the teats were not predipped but were wiped with a single-use cloth towel. The milking unit was attached within 60 $\mathrm{s}$ of preparation.

\section{Preparation of Challenge Suspensions}

Staph. aureus Challenge Suspension. Three times weekly, Staph. aureus, ATCC 29740 (American Type Culture Collection, Rockville, Maryland), was inoculated into a 6 -mL tube of trypticase soy broth (TSB) and incubated at $37^{\circ} \mathrm{C}$ for 5 to $7 \mathrm{~h}$. The stock culture was streaked on blood agar to confirm sterility. Using TSB to dilute the culture, a concentration of approximately $5.0 \times 10^{7} \mathrm{cfu} / \mathrm{mL}$ was estimated by optical density spectrophotometry. At that time, $1 \mathrm{~mL}$ of the $6 \mathrm{~mL}$ of culture was aseptically transferred to $500 \mathrm{~mL}$ of TSB and incubated at $37^{\circ} \mathrm{C}$ for 16 to $18 \mathrm{~h}$. The bacterial cells were pelleted by centrifugation, washed twice with $0.1 \%$ proteose-peptone solution, and subsequently resuspended in proteose-peptone solution. The stock suspension was separated into aliquots and stored at $5^{\circ} \mathrm{C}$. A standard plate count was conducted on each aliquot (National Mastitis Council, 1999).

Strep. agalactiae Challenge Suspension. Three times weekly, Strep. agalactiae, ATCC 27956, was inoculated into a 6-mL tube of TSB and incubated at $37^{\circ} \mathrm{C}$ for $15 \mathrm{~h}$. Subsequently, $1 \mathrm{~mL}$ of the $6 \mathrm{~mL}$ of culture was aseptically transferred into $500 \mathrm{~mL}$ of TSB and incubated at $37^{\circ} \mathrm{C}$ for 6 to $7 \mathrm{~h}$. Using TSB to dilute the culture, a concentration of approximately $5.0 \times 10^{7}$ $\mathrm{cfu} / \mathrm{mL}$ was achieved by optical density spectrophotometry. The stock suspension was separated into aliquots and stored at $5^{\circ} \mathrm{C}$ until further use.

Premilking Challenge Broth Preparation. The challenge broth was removed from storage prior to the start of milking. At that time, the aliquot was warmed in a $37^{\circ} \mathrm{C}$ hot water bath and, following a 30 -min incubation, the broths containing Strep. agalactiae and Staph. aureus were combined. A regular reconciliation procedure was followed by reculturing the stock cultures used on farm in the mastitis research laboratory. This process has always shown that the challenge solutions are viable and in the same log unit as described in the protocol for the challenge system.

\section{Challenge of Teats and Application of Teat Disinfectants}

Immediately following every milking, each teat was challenged by immersion $(25 \mathrm{~mm})$ in a teat dip-cup of prepared TSB suspension of Strep. agalactiae and Staph. aureus. After the challenge, the bacterial suspension was left to air-dry on the teats (2 to $4 \mathrm{~min}$ ). The right front and left hind teats were dipped in the test teat disinfectant (experimental $0.5 \%$ hydrogen peroxide teat disinfectant product; DeLaval), whereas the right hind and left front teats were dipped in the commercially available $0.5 \%$ hydrogen peroxide teat disinfectant (Oxy-Gard, EcoLab, St. Paul, MN), as a positive control. The use of this positive control method under conditions of experimental challenge has recently been reported (Leslie et al., 2005).

\section{Sample Collection and Bacteriological Culturing of Milk}

During the trial period, quarter foremilk samples were aseptically collected each week at the Monday a.m. milking. Sampling and bacteriological procedures were conducted according to the guidelines in the Laboratory Handbook on Bovine Mastitis (National Mastitis Council, 1999). All quarter samples were analyzed for SCC using a Bentley Somacount 300 (Bentley Instruments Inc., Chaska, MN). The bacteriological infection status of each quarter prior to the start of the challenge was established by weekly samples before the challenge period commenced. Growth of 3 or more colony types on the culture of any sample was considered contaminated, and the quarter was resampled at the Thursday p.m. milking to determine infection status. In addition, any quarter that was newly positive with a Strep. agalactiae 
or Staph. aureus isolate was resampled at the Thursday p.m. milking to confirm the new IMI. The SCC data were also used as a screening tool to identify quarters that were negative on bacteriological culture yet had elevated SCC greater than 300,000 cells $/ \mathrm{mL}$. Quarters that met these criteria were resampled and submitted for culture.

\section{Determination of a Positive Quarter}

A quarter was diagnosed as positive for a new IMI when any of the following criteria were met:

- Signs of clinical mastitis were found, in which a duplicate milk sample had been aseptically collected to confirm the presence of bacteria prior to treatment.

- Staphylococcus aureus or Strep. agalactiae was cultured in moderate or large numbers (greater than or equal to $5.0 \times 10^{2} \mathrm{cfu} / \mathrm{mL}$ ) on 2 successive samples.

- Staphylococcus aureus, Strep. agalactiae, Staphylococcus spp., or Corynebacterium bovis was cultured in low numbers $\left(1.0 \times 10^{2}\right.$ to $\left.5.0 \times 10^{2} \mathrm{cfu} / \mathrm{mL}\right)$ on 3 successive samples.

If a quarter was classified as positive by any of the above criteria, it was treated with a cephapirin sodium (CefaLak, Wyeth Laboratories, Guelph, Ontario) intramammary infusion, repeated once at $12 \mathrm{~h}$, and removed from further exposure to the experimental challenge culture. Early treatment of new IMI was intended to reduce the exposure of uninfected quarters to the challenge organism from the infected gland during the milking procedure, which would be beyond the intended experimental challenge. The rate of elimination of IMI was not examined in the current study.

\section{Evaluation of Teat Skin and Teat End Condition}

Teats were examined once weekly throughout the study period for teat skin condition, teat end roughness, and teat end thickness. Teat skin condition was assessed using a previously published protocol (Goldberg et al., 1994). Briefly, teat skin was scored on an ordinal scale of 1 to 5 . A score of 1 was smooth teat skin free from scales, cracks, or chapping; score 2 was teat skin showing some evidence of slight drying; score 3 was chapped teat skin with more severe drying and small cracks present; score 4 was chapped teat skin with pronounced cracks and redness; and score 5 was severely damaged and ulcerative skin with scabs or open lesions. In addition, teat end conformation was evaluated following published guidelines (Goldberg et al., 1994). A pictorial chart to define this classification system was established using information from the Teat Club International (Mein et al., 2001). A 4-point teat end thickness score was established and used. A teat end thickness score of 1 signified that the teat end was level with the rest of the teat shape. A teat end thickness score of 4 was a severely raised end to a height of greater than 2 $\mathrm{mm}$. One research technician who was previously trained in using these ordinal scales performed all teat skin and teat end examinations.

\section{Statistical Methods}

Statistical analyses were conducted following procedures described previously by Nickerson et al. (2004). A sample size calculation was not performed prior to the study because all available cows in the PDRC herd were used. According to NMC guidelines (Nickerson et al., 2004), assuming a confidence level of $5 \%$ and a power of $80 \%$, to detect a difference in new IMI between the 2 treatment groups as large as $30 \%$ in controls and $20 \%$ in the treated group, 339 quarters per group would have been required. A one-tailed $z$-statistic was calculated based on the difference in IMI between quarters dipped with the experimental product and those dipped in the positive control product. The equation used was as follows:

$$
z=\left[x_{1} / n_{1}-x_{2} / n_{2}\right] /\left[p \times(1-p) / n_{1}+p \times(1-p) / n_{2}\right]^{1 / 2},
$$

where $x_{1}$ is the number of new IMI in the quarters dipped in the positive control, $x_{2}$ is the number of new IMI in the quarters dipped in the experimental product, $n_{1}$ is the number of quarters dipped in the positive control, $n_{2}$ is the number of quarters dipped in the experimental product, and $p=\left(x_{1}+x_{2}\right) /\left(n_{1}+n_{2}\right)$. The percentage reduction of new IMI is $100\left[\left(x_{1} / n_{1}\right)-\left(x_{2} / n_{2}\right)\right] /$ $x_{1} / n_{1}$.

Statistical significance was evaluated based on onetailed standard normal tables. To account for the correlation of quarters within cows and to examine the effect of treatment on teat skin and teat end scores, further analyses were conducted in SAS for Windows, version 8.2 (SAS Institute, 1999-2000). A $2 \times 2$ contingency table was created to calculate the odds ratio $(\mathbf{O R})$ and relative risk of developing a new IMI based on the teat dip applied, and Pearson's $\chi^{2}$ was used to determine significance. If there was evidence of significance $(P<$ 0.10 ), then a logistic model, using the GENMOD procedure (Proc Genmod; SAS Institute, 1999-2000), was used to control for this correlation and thus better estimate the effect of treatment group on new infection rates and on teat skin condition seen in this trial. 
Table 1. Summary of new IMI data for an experimental product containing $0.5 \%$ hydrogen peroxide as the active ingredient and a commercially available $0.5 \%$ hydrogen peroxide teat disinfectant against Staphylococcus aureus and Streptococcus agalactiae under experimental challenge conditions in 45 dairy cows

\begin{tabular}{|c|c|c|c|c|c|c|c|c|c|c|c|c|c|}
\hline \multirow{3}{*}{$\begin{array}{l}\text { Organism } \\
\text { and } \\
\text { treatment }\end{array}$} & \multirow{3}{*}{$\begin{array}{l}\text { Quarters } \\
\text { eligible } \\
\text { for new IMI }\end{array}$} & \multicolumn{12}{|c|}{ New IMI } \\
\hline & & \multicolumn{11}{|c|}{ Week } & \multirow{2}{*}{$\begin{array}{l}\text { Quarters } \\
\text { infected, \% }\end{array}$} \\
\hline & & 1 & 2 & 3 & 4 & 5 & 6 & 7 & 8 & 9 & 10 & Total & \\
\hline \multicolumn{14}{|l|}{ Staph. aureus } \\
\hline Experimental & 89 & 6 & 6 & 2 & 5 & 2 & 1 & 0 & 0 & 1 & 1 & 24 & 27.0 \\
\hline Positive control & 89 & 3 & 3 & 2 & 2 & 2 & 3 & 0 & 0 & 0 & 1 & 16 & 18.0 \\
\hline \multicolumn{14}{|l|}{ Strep. agalactiae } \\
\hline Experimental & 89 & 1 & 0 & 0 & 2 & 0 & 2 & 1 & 0 & 0 & 0 & 6 & 6.7 \\
\hline Positive control & 89 & 0 & 1 & 0 & 0 & 2 & 0 & 0 & 0 & 1 & 0 & 4 & 4.5 \\
\hline
\end{tabular}

To evaluate the effect of the disinfectant on teat skin and teat end health, 3 different statistical approaches were used. First, 2 traditional statistical methods were used, which did not account for the correlation of quarters within cows or for repeated measures. The mean teat skin and teat end condition scores from each week of the study were compared using a Student's $t$-test. In addition, the Wilcoxon signed rank test was used, which is appropriate for paired evaluations on nonparametric data. To appropriately account for the correlations and the repeated measures in these data, a summary statistic was calculated based on scores collected each week, and this statistic was then formally tested using the mixed procedure (Proc Mixed; SAS Institute, 19992000), controlling for the score prior to commencing the study.

\section{RESULTS AND DISCUSSION}

New infection data collected weekly over the trial period are shown in Table 1. A total of 24 new IMI caused by Staph. aureus were detected in the quarters treated with experimental teat disinfectant, and 16 new Staph. aureus infections were detected in the positive control product group. Totals of 6 and 4 quarters in the experimental and positive control groups, respectively, became infected with Strep. agalactiae over the study period (Table 1). Determination of the absolute value of the $z$-statistic revealed no statistically significant difference between the experimental and positive control postmilking teat disinfectants among the percentage of quarters becoming infected with either challenge pathogen. The $z$-statistic approached the critical value for new IMI caused by Staph. aureus $(z=1.44)$. However, for both pathogen groups the $z$-statistic was lower than the 1.645 needed to demonstrate a statistically significant difference in new IMI. The odds of a quarter becoming infected with Staph. aureus were not significantly different between the 2 teat dip treatments $(\mathrm{OR}=1.68$; $P=0.15)$. Similarly, the odds of developing a new IMI by Strep. agalactiae $(\mathrm{OR}=1.5)$ did not differ between the 2 teat dips $(P=0.51)$. Therefore, based on the $z$ statistic and on $\chi^{2}$ testing of the OR between both challenge groups, no further statistical modeling of the infection data was performed. There were concerns about whether the statistical power was sufficient to detect small differences between treatment groups in this experimental design. A report was recently published in which a positive control postmilking teat disinfectant was evaluated under conditions of experimental challenge (Leslie et al., 2005), and similar concerns with the statistical power to detect differences between treatment groups were described.

The 2 analytical approaches provided similar results. However, it should be noted that if the calculation of the OR and relative risk had found significant results, a more complex statistical analysis that allowed for the proper control of potentially confounding variables would have been warranted. This is of particular importance for studies using a negative control group, in which the difference in the rate of new IMI is typically much more pronounced. Although the method using the $z$-statistic has been widely used and accepted, the use of more advanced approaches in modeling these data may provide a more appropriate analysis of the results. In addition, it would be relevant to investigate the differences in overall infection rates, as well as the time to new IMI, by means of survival models.

Teat end condition and teat end thickness (height) scores were recorded once weekly throughout the study period (Table 2). The average teat end condition score was 2.3 for both treatment groups. The mean teat end height score was 1.7 for both treatment groups. There were no significant differences between the 2 products for either of these measures of teat health. The teat skin condition results are shown in Figure 1. Differences were seen in the mean teat skin condition scores in most weeks over the 10 -wk study period. Overall, the mean teat skin condition score was 1.7 for the experimental teat disinfectant group and 2.0 for the positive 
Table 2. Average teat end condition and teat end thickness scores ${ }^{1}$ for quarters of 45 dairy cows dipped with an experimental product containing $0.5 \%$ hydrogen peroxide as the active ingredient or a commercially available $0.5 \%$ hydrogen peroxide teat disinfectant

\begin{tabular}{|c|c|c|c|c|c|c|c|c|c|c|c|c|}
\hline \multirow[b]{2}{*}{ Variable assessed } & \multicolumn{11}{|c|}{ Week } & \multirow[b]{2}{*}{ Mean } \\
\hline & Pretrial & 1 & 2 & 3 & 4 & 5 & 6 & 7 & 8 & 9 & 10 & \\
\hline \multicolumn{13}{|l|}{ Teat end condition } \\
\hline Experimental dip & 2.0 & 2.0 & 2.3 & 2.2 & 2.5 & 2.7 & 2.4 & 1.7 & 2.0 & 2.6 & 2.5 & 2.3 \\
\hline Positive control dip & 2.0 & 2.1 & 2.2 & 2.1 & 2.5 & 2.7 & 2.4 & 1.7 & 2.0 & 2.7 & 2.5 & 2.3 \\
\hline \multicolumn{13}{|l|}{ Teat end thickness } \\
\hline Experimental dip & 1.6 & 1.5 & 1.8 & 1.8 & 1.5 & 1.5 & 2.0 & 1.2 & 1.4 & 2.0 & 2.1 & 1.7 \\
\hline Positive control dip & 1.7 & 1.6 & 1.8 & 1.9 & 1.4 & 1.6 & 1.9 & 1.2 & 1.4 & 2.0 & 2.1 & 1.7 \\
\hline
\end{tabular}

${ }^{1}$ Teat end condition and teat end thickness scores were recorded once weekly for $10 \mathrm{wk}$ using an ordinal scale (1 to 5). Teat end scores: $1=$ teat end sphincter is smooth, with no evidence of irritation; $2=$ teat end sphincter has a raised but smooth ring; $3=$ teat end sphincter is roughened, with slight radial cracks but no redness is present; $4=$ teat end sphincter is everted, with severe radial cracking; $5=$ teat end sphincter is severely damaged and ulcerative, with scabs or open lesions. Teat end thickness scores: $1=$ teat end is level with the rest of the teat shape; $2=$ teat end is slightly raised (about 0 to $1 \mathrm{~mm}$ ); $3=$ teat end is moderately raised (about 1 to $2 \mathrm{~mm}$ ); 4 = teat end is severely raised (greater than $2 \mathrm{~mm}$ ).

control group $(P<0.05)$. Traditional analysis of teat skin condition changes (Wilcoxon signed rank test and the $t$-test) supported improved (lower) scores with the test teat disinfectant. In fact, with all 3 statistical tests used, the experimental disinfectant showed significantly improved teat skin condition scores. The mixed model provided an estimate of the difference between the mean teat skin condition scores, which revealed that skin condition was improved by 0.04 units with the experimental product compared with the control product $(P=0.03)$. Therefore, the experimental product resulted in significantly improved teat skin health, compared with the commercially available positive control product, for the duration of the 10-wk study period.

Two points should be emphasized from this study. First, the study was conducted during the early summer months, a time when the teat condition is normally of less concern than during conditions of more extreme

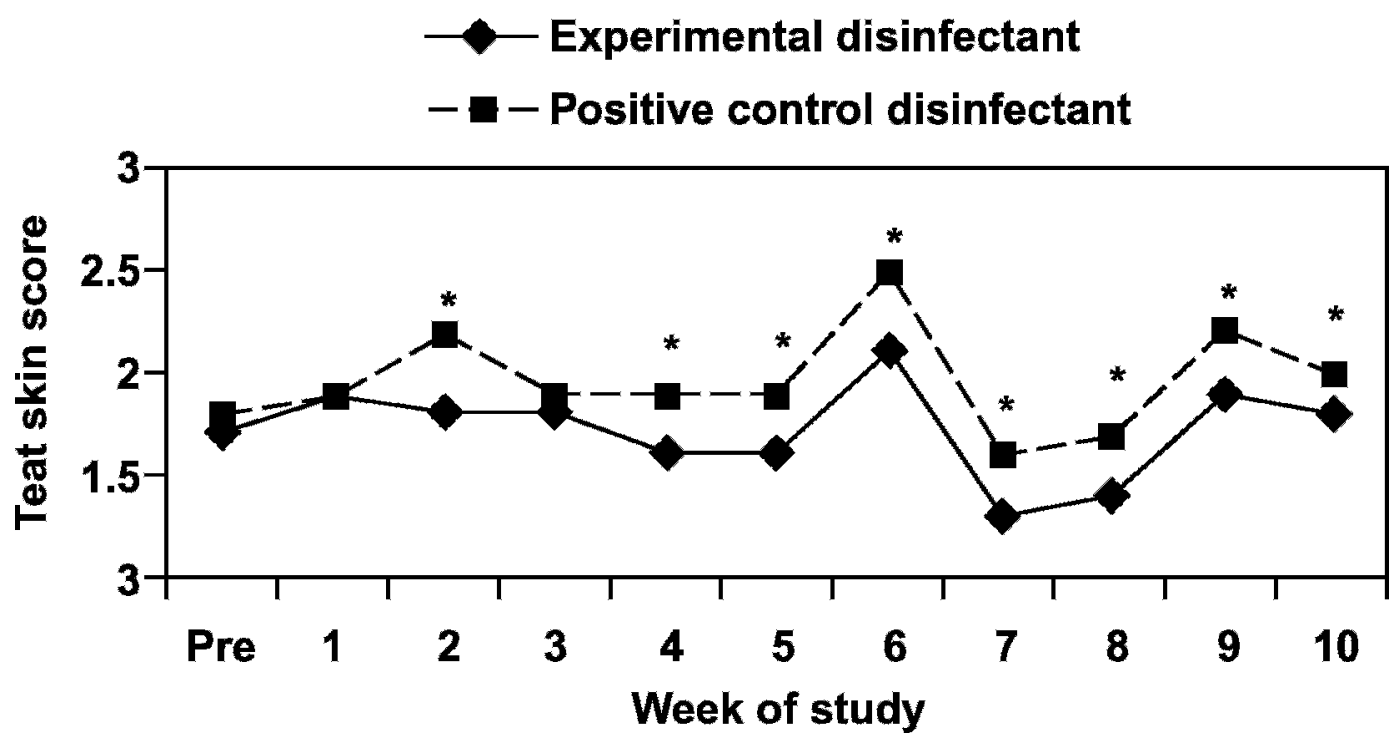

Figure 1. Average teat skin scores for quarters dipped with an experimental product containing $0.5 \%$ hydrogen peroxide as the active ingredient and those dipped with a commercially available $0.5 \%$ hydrogen peroxide teat disinfectant, recorded once weekly during a 10 -wk experimental study. Teat skin scores: $1=$ teat skin is smooth and free from scales, cracks, or chapping; $2=$ teat skin shows some evidence of slight drying, and white lines are visible; 3 = teat skin is chapped, and more severe drying and small cracks are present; $4=$ teat skin is chapped, and pronounced cracks appear with redness; 5 = teat skin is severely damaged and ulcerative, with scabs or open lesions. An asterisk $(*)$ indicates different teat skin scores between the two treatments at observed times using traditional statistical techniques $(P<$ 0.05). Student's $t$-test and Wilcoxon signed rank test detected improved (lower) teat skin scores throughout the study, with no estimate of the magnitude. A repeated-measures analysis also detected a difference between the disinfectants in the teat skin scores $(P<0.05)$ and estimated the difference in least squared means to be 0.04 units. 
temperature change in the late fall and winter months. To determine whether the improvements in teat skin condition observed with the use of the experimental hydrogen peroxide product were meaningful throughout all seasons, it may be useful to conduct an experiment over a more extended period of time that would include periods when low temperatures and windchill are more prominent factors.

Second, from an analytical standpoint, a discussion on biological vs. statistical significance is warranted. Leslie et al. (2005) discussed the statistical power of techniques used to analyze teat disinfectant data. The situation often arises when very minor changes in teat end and teat skin condition scores are detected that may not be biologically important to functionality or health. The scoring system used in this study was an ordinal scale of 1 to 5, with 1-unit increments. An improvement in teat skin score of 0.04 units, as determined by least squares means using the mixed model, may appear to be minor, although Figure 1 shows a difference of about 0.3 units between treatments in the weekly average for most weeks during the study period. One alternative method has been to analyze only data from the beginning (wk 1), middle (wk 5), and end of the trial (wk 9; Leslie et al., 2005). When a similar approach was taken with data from the current study, there was no longer a significant effect of treatment on teat skin condition $(P=0.32)$. As such, it becomes incumbent upon the reader to assess the biological significance of the data reported.

\section{CONCLUSIONS}

The efficacy of the experimental hydrogen peroxidebased teat disinfectant and the commercially available positive control product for preventing new Staph. aureus and Strep. agalactiae IMI under experimental challenge conditions did not differ significantly. These findings suggest that the test teat disinfectant provided germicidal activity similar to that of the positive control teat disinfectant. Average teat skin condition scores were significantly improved when the experimental dis- infectant was applied over the 10 -wk study period. The teat end condition and teat end thickness scores were not significantly different between the 2 hydrogen peroxide teat dips studied.

\section{ACKNOWLEDGMENTS}

The investigators gratefully acknowledge the scientific and financial support of DeLaval Company (Kansas City, MO). The efforts of the manager and staff of the Ponsonby Dairy Research Station, University of Guelph, are greatly appreciated.

\section{REFERENCES}

Boddie, R. L., W. E. Owens, C. J. Foret, and P. Janowicz. 2004. Efficacy of a $0.1 \%$ iodine teat dip against Staphylococcus aureus and Streptococcus agalactiae during experimental challenge. J. Dairy Sci. 87:3089-3091.

Goldberg, J. J., A. J. Bramley, P. A. Drechsler, T. C. Hemling, J. L. Jones, J. K. O’Neil, M. Winicov, and J. W. Pankey. 1994. Evaluation of teat conditioning qualities of post-milking teat dips. Page 334 in Natl. Mastitis Council Mtg. Proc., Orlando, FL. Natl. Mastitis Council, Arlington, VA.

Leslie, K. E., C. S. Petersson, E. Vernooy, and A. Bashiri. 2005. Efficacy of an iodophore teat disinfectant against Staphylococcus aureus and Streptococcus agalactiae in experimental challenge. J. Dairy Sci. 88:406-410.

Mein, G. A., F. Neijenhuis, W. F. Morgan, D. J. Reinemann, J. E. Hillerton, J. R. Baines, I. Ohnstad, M. D. Rasmussen, L. Timms, J. S. Britt, R. Farnsworth, N. Cook, and T. Hemling. 2001. Evaluation of bovine teat condition in commercial dairy herds: Noninfectious factors. Pages 347-351 in Int. Symp. Mastitis and Milk Quality Mtg. Proc., Vancouver, BC, Canada. Natl. Mastitis Council, Madison, WI.

National Mastitis Council. 1999. Laboratory Handbook on Bovine Mastitis. Natl. Mastitis Council, Madison, WI.

National Mastitis Council. 2004. Summary of peer-reviewed publications on efficacy of pre-milking and post-milking teat disinfectants published since 1980. Pages 245-258 in Natl. Mastitis Council Mtg. Proc., Orlando, FL. Natl. Mastitis Council, Madison, WI.

Nickerson, S. C., A. Saxon, L. K. Fox, T. Hemling, J. S. Hogan, J. Morelli, S. P. Oliver, W. E. Owens, M. Pawlak, and L. G. Petersson. 2004. Efficacy evaluation of post-milking teat germicides: Updated protocols. Pages 379-398 in Proc. Natl. Mastitis Council Annu. Mtg., Charlotte, NC. Natl. Mastitis Council (NMC), Madison, WI.

Radostits, O. M. 1994. Herd Health: Food Animal Production Medicine. 3rd ed. W.B. Saunders, Philadelphia, PA.

SAS Institute. 1999-2000. SAS User's Guide: Statistics, Version 8.2. SAS Institute, Cary, NC. 